\title{
Pyloric Atresia- A Case Report
}

\author{
A HANIF ${ }^{1}$, K HASINA $^{2}$, K HASSAN $^{3}$, ASM HASANUZZAMAN ${ }^{4}$, N ISLAM $^{5}$, AZ HOSSAIN $^{6}$, MQ-K TALUKDER $^{7}$
}

\section{Introduction}

Infantile hypertrophic pyloric stenosis (IHPS) is a common cause of gastric outlet obstruction in infant. The prevalence of IHPS ranges from 1.5 to 4.0 in 1000 live birth ${ }^{1}$. But the incidence of IHPS has been increasing approximately from 1.5 to 4.0 in 1000 live birth to $1: 150^{2}$. Though pyloric atresia is a very uncommon cause of gastric outlet obstruction in infant but atresia in this region occurs in the form of web, membrane/diaphragm or rarely solid cord ${ }^{3}$. Membrane/ diaphragm may be single or double and may be perforated or imperforated ${ }^{3,4}$. If the size of perforation is less than $10 \mathrm{~mm}$, it causes complete obstruction ${ }^{5,6}$. We report the presentation and management of such a child.

\section{Case Report}

A 16 months old female baby, third born, full term, delivered by caesarean section for polyhydramnios, weight $5.5 \mathrm{~kg}$, of nonconsanguineous parents brought with, recurrent vomiting since birth and failure to thrive. The child developed vomiting just after birth when first feed was given, the baby vomited several times daily, sometimes just after feed and sometimes few minutes later, vomits containing ingested food material, which was projectile, nonbilious and foul smelling. Her appetite was normal and the baby was suffering from constipation since birth. There was no history of repeated attack of respiratory problem, her micturation was normal. First sibling was died just after birth but cause was not known. With such complaints, this baby admitted several times in the department of paediatric medicine at different hospitals and treated conservatively.

Examination revealed that the baby was ill looking, sign of some dehydration was present and abdomen

1. Assistant Professor, Department of Paediatric Surgery, Dhaka Medical College \& Hospital, Dhaka, E-mail:ahaniftablu @hotmail.com

2. Assistant Professor, Department of Paediatric Surgery, Dhaka Medical College \& Hospital, Dhaka

3. Registrar, Department of Paediatric Surgery, Dhaka Medical College \& Hospital, Dhaka

4. Medical Officer, Surgery OPD, Dhaka Medical College \& Hospital, Dhaka

5. Assistant Registrar, Department of Paediatric Surgery, BSMMU, Dhaka

6. Associate Consultant, Department of Paediatric Surgery \& In-charge Emmergency, Square Hospitals Ltd., Dhaka

6. Professor of Paediatrics

Correspondence: Dr. Abdul Hanif was scaphoid with epigastric fullness, visible peristalsis was present in the epigastic region, abdomen was soft, non tender and no palpable lump and tympanitic on percussion and bowel sound was present. Genitalia and perineum was normal. Other systemic examination revealed no abnormalities.

X-ray abdomen in erect posture including both dome of diaphragm showed no abnormality. USG of whole abdomen special attention to pylorus showed, stomach, moderately dilated with fluid and food residues. The appearance of pylorus was not consistent with IHPS. Ba-swallow esophagus showed no organic lesion in pharynx and esophagus, no hiatus hernia, no gastroeosophageal reflux. Ba-meal X-ray showed gastric emptying was delayed indicating some outlet obstruction in the pyloroduodenal region and stomach was hugely enlarged.

Preoperative preparation was done with fluid and electrolyte correction. Baby was also kept nothing by mouth with nasogastric suction and was subjected to laparotomy through supraumbilical transverse incision under general anesthesia. At operation, the stomach was hugely dilated and duodenum found normal in diameter but there was a circular indentation narrowing at the pylorus (Fig.-1). Other organs were normal. A longitudinal incision was made at pyloroduodenal region and found a thick circular membrane with central hole at the distal part of pylorus (Fig.-2). The membrane was excised and pyloroduodenoplasty was done transversely (Fig.-3).

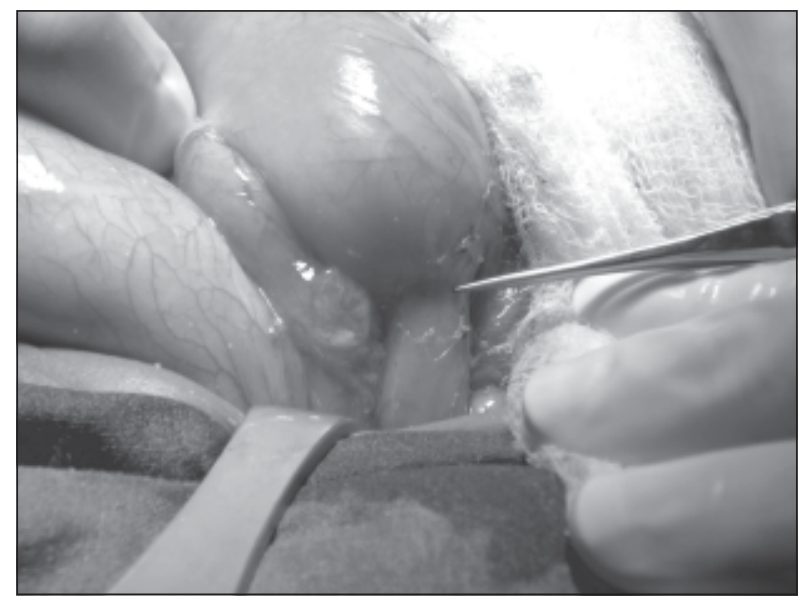

Fig.-1: Indentation at the junction of pylorus and duodenum 


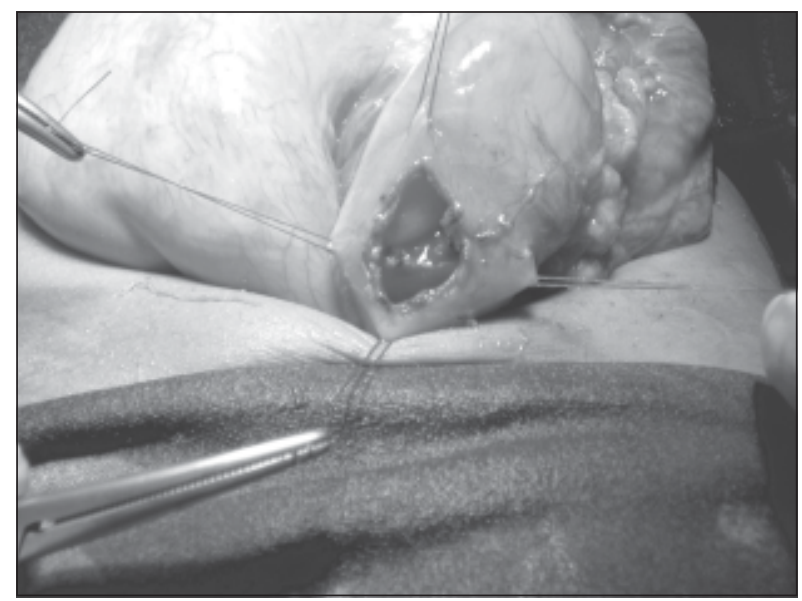

Fig.-2: Interior of pyloroduodenal junction - a thick membrane

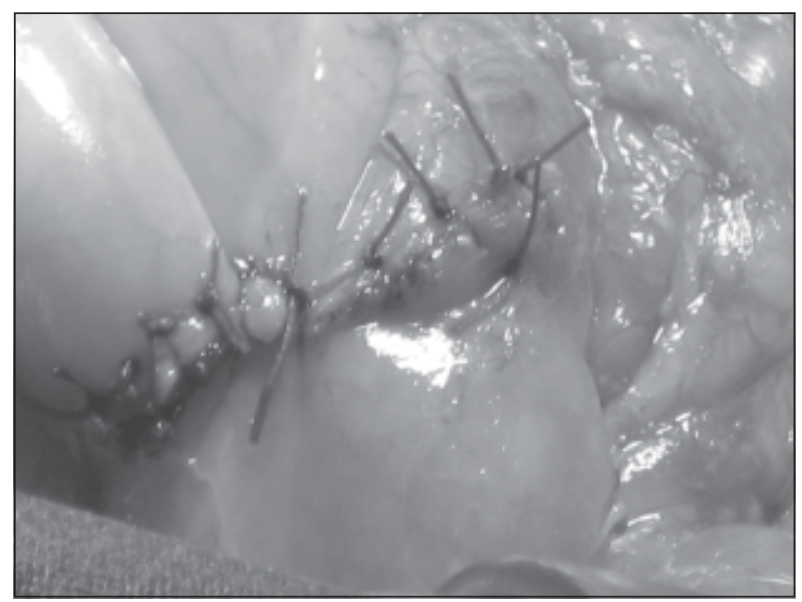

Fig.-3: After pyloroduodenoplasty

At review, 15 days after discharge, the child gained $0.5 \mathrm{~kg}$ body weight and was doing well and no complaint of vomiting. After 3 months she gained another $2 \mathrm{~kg}$ and her weight was $8 \mathrm{~kg}$.

\section{Discussion}

Pyloric atresia occurs in the form of webs, membrane/ diaphragm or rarely solid cord ${ }^{3,4}$. The cause of antral web and artesia has not been fully elucidated ${ }^{4,7}$. Numerous proposals have been made to explain the occurrence of this rare anomaly. It is generally believed that intrauterine vascular accident causes ischemic necrosis and subsequent bowel artesia but it is unlike for this to occur in the stomach, because the blood supply is abundant ${ }^{6,7}$. It is also difficult to envisage the possibility of failure of recanalization as has been proposed as a cause of fetal bowel obstruction, because there is no firm evidence that such occlusion ever occurs in the stomach ${ }^{8}$. Skandalakis and Gray have postulated that redundancy and slipping of epithelial lining may initiate the formation of an incomplete diaphragm ${ }^{9}$. Sharma and associates also hypothesized the etiology on a small series of acquired mucosal obstruction of the pylorus. Although this explanations appear to be a possible cause of membrane, webs, it still remains speculative and definite confirmatory evidence is not currently available . $^{2}$

So whatever the cause is, a child presented with persistent vomiting, failure to thrive, barium meal $x$ ray showed dilated stomach and failure to medical treatment should be evaluated carefully for a surgical cause and laparotomy should be performed without undue delay - not wait and see, the strategy should be open and see and correct it !!

\section{References}

1. Jeb MB, Melton J, Griffin MR, Kaufnan B, Hoffman AD, Braeghton D, et al. Factors associated with IHPS. Am J Dis Child 1998;142: 334-37.

2. Laron Z, Horne LM. Incidence of IHPS. Am J Dis Child 1998; 151: 1957.

3. Bell MJ, Ternberg JL, McAlister W, Keating JP, Tedesco FJ. Antral diaphragm, a cause of gastric outlet obstruction in infants and children. J Pediatr 1977; 90: 196-202.

4. Heller JA, Cahill JL. Combined congenital gastric and duodenal obstruction: pitfalls in diagnosis and treatment. Surgery 1968; 63: 503-06.

5. Tumeal WP, Smith El. Antral webs in infancy. J Pediatr Surg 1980; 15: 152-55.

6. Weissman A, Achiron R, Kuint J, Lipitz S, Mashiach S, Avigad I. Prenatal diagnosis of congenital gastric outlet obstruction. Prenat Diag 1994; 14: 888-91.

7. Skandalakis JE, Gray SW. Embryology of surgeon. Baltimore: Williams and Wilkins; 1994.

8. Bronsthar B, Nandeau MR, Abrams MW. Congenital pyloric atresia: Areport of three cases and review of literature. Surgery 1971; 69: 13036.

9. Dessanti A, Lannuccelli M, Dore A, Meloni BG, Niolu P. Pyloric Artesia an attempt of anatomic pyloric sphincter reconstruction. J Pediatr Surg 2000; 35: 1372-74. 